\title{
Implementasi Sistem Load Balancing Dua ISP Menggunakan Mikrotik dengan Metode Per Connection Classfier
}

\author{
Prihatin Oktivasari, Rinaldi Sanjaya \\ Konsentrasi Teknik Komputer dan Jaringan \\ Program Studi Teknik Informatika \\ Jurusan Teknik Informatika dan Komputer \\ Politeknik Negeri Jakarta \\ Depok, Jakarta \\ prihatin.oktivasari@tik.pnj.ac.id, rsanjayar@gmail.com
}

Diterima: 15 September 2015. Disetujui: 13 Oktober 2015. Dipublikasikan: November 2015

\begin{abstract}
Abstrak - Sistem Load Balancing dapat membuat kinerja internet menjadi lebih optimal. Dengan pembagian jalur traffic yang lebih merata membuat sistem Load Balancing menjadi solusi yang bagus untuk kinerja internet yang lebih stabil. Dalam melakukan konfigurasi, system Load Balancing ini dilakukan pada mikrotik. Mikrotik yang digunakan adalah Mikrotik RB2011UiAS-RM. Terdapat beberapa metode yang biasa. Salah satunya adalah Per Connection Classifier (PCC). Metode ini pula yang akan digunakan dalam penulisan laporan ini. Selain PCC, metode lain yang ada pada Load Balancing adalah ECMP (Equal Cost Multi Path), Nth, dan juga Static Route dengan address list. Load Balancing dengan menggunakan metode PCC adalah teknik untuk mendistribusikan beban traffic pada 2 jalur koneksi menjadi lebih seimbang agar traffic dapat berjalan optimal, memaksimalkan throughput, memperkecil waktu tanggap dan menghindari overload pada salah satu jalur koneksi. Kelebihan yang dimiliki metode PCC adalah mampu menspesifikasikan gateway untuk setiap paket data yang masih berhubungan dengan data yang sebelumnya sudah dilewatkan pada salah satu gateway.
\end{abstract}

Kata Kunci: Load Balancing, bandwidth, mikrotik RB2011UiAS-RM, per connection classifier (PCC), internet service provider (ISP).

\section{PENDAHULUAN}

Jaringan komputer bukan merupakan sesuatu yang baru saat ini. Hampir di setiap instansi pendidikan terdapat jaringan komputer untuk memperlancar arus informasi di dalam instansi tersebut bahkan di perumahan dan perusahaan juga sudah menggunakannya. Internet yang sudah populer saat ini adalah suatu jaringan komputer raksasa yang merupakan jaringan komputer yang terhubung dan dapat saling berinteraksi.
Load Balancing diperlukan karena dapat membuat kinerja internet menjadi lebih cepat dengan memaksimalkan pembagian beban traffic yang dilakukan pada mikrotik [1].

Hal ini dapat terjadi karena adanya perkembangan teknologi jaringan yang sangat pesat, sehingga dalam beberapa tahun saja jumlah pengguna jaringan komputer yang tergabung dalam internet berlipat ganda. Perkembangan pemakaian internet yang meningkat pesat saat ini menyebabkan permintaan akan mutu layanan (Quality of services/QoS) yang harus ditingkatkan. Terutama bagi penyedia layanan internet (Internet Service Provider/ISP) bahkan di jaringan pribadi dan instansi yang menggunakan internet sebagai kebutuhan utama.

\section{TINJAUAN PUSTAKA}

\section{A. Pengertian Load Balancing}

Load Balancing adalah proses pendistribusian beban terhadap sebuah servis yang ada pada sekumpulan server atau perangkat jaringan ketika ada permintaan dari pengguna [2]. Ketika banyak permintaan dari pengguna maka server tersebut akan terbebani karena harus melakukan proses pelayanan terhadap permintaan pengguna.

Load Balancing dengan 2 ISP ditunjukkan pada Gambar 1. 


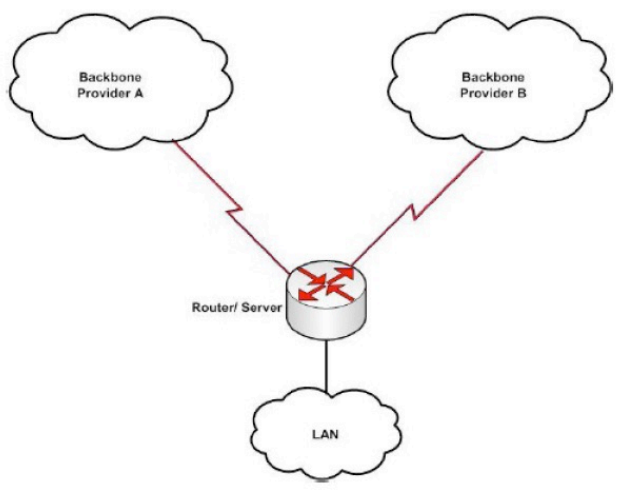

Gambar 1. Load Balancing dengan 2 ISP

Solusi yang cukup bermanfaat adalah dengan membagi beban yang datang ke beberapa server, Jadi tidak berpusat ke salah satu server jaringan saja. Teknologi itulah yang disebut Teknologi Load Balancing. Dengan teknologi Load Balancing maka dapat diperoleh keuntungan seperti menjamin reabilitas servis, availabilitas dan skalabilitas suatu jaringan [3]. Keuntungan menggunakan Load Balancing adalah jika salah satu line speedy bermasalah maka koneksi internet tidak akan terputus karena masih ada line speedy yang satu. Tapi jika menggunakan model konvensional bila salah satu line speedy mengalami gangguan maka semua komputer yang terhubung dengannya akan mengalami ganggguan koneksi.

\section{B. Metode Load Balancing}

Metode Load Balancing sendiri ada 4 cara yang umum dipergunakan. Diantaranya Static Route dengan Address List, Equal Cost Multi Path (ECMP), Nth, dan Per Connection Classifier (PCC). Masingmasing metode mempunyai kelebihan, kekurangan dan karakteristiknya masing-masing [4].

Load Balancing dengan menggunakan konsep PCC ini adalah teknik untuk mendistribusikan beban trafik pada dua atau lebih jalur koneksi supaya seimbang, agar trafik dapat berjalan optimal, memaksimalkan throughput, memperkecil waktu tanggap dan menghindari overload pada salah satu jalur koneksi. Kelebihan yang dimiliki metode PCC adalah mampu menspesifikasikan gateway untuk tiap paket data yang masih berhubungan dengan data yang sebelumnya sudah dilewatkan pada salah satu gateway [5]. Sementara kekurangan dari metode ini lebih memungkinkan beresiko terjadi overload pada salah satu gateway yang disebabkan oleh pengaksesan situs yang sama.

\section{Synching}

Winbox adalah sebuah utility yang digunakan untuk melakukan remote ke server Mikrotik kita dalam mode GUI. Jika untuk mengkonfigurasi Mikrotik dalam text mode melalui PC itu sendiri, maka untuk mode GUI yang menggunakan Winbox ini kita mengkonfigurasi Mikrotik melalui komputer client. Gambar 2 menunjukkan logo Winbox.

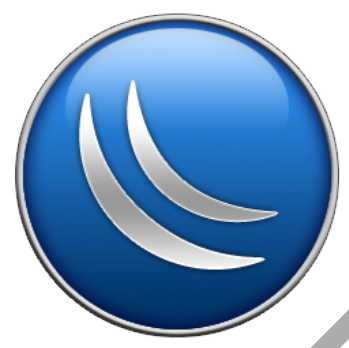

Gambar 2. Logo Winbox

\section{OwnCloud}

Mikrotik adalah sebuah sistem operasi termasuk di dalamnya perangkat lunak yang dipasang pada suatu komputer sehingga komputer tersebut dapat berperan sebagai jantung network, pengendali atau pengatur lalu-lintas data antar jaringan, komputer jenis ini dikenal dengan nama router. Jadi intinya Mikrotik adalah salah satu sistem operasi khusus untuk router. Mikrotik dikenal sebagai salah satu Router OS yang handal dan memiliki banyak sekali fitur untuk mendukung kelancaran network. Gambar 3 menunjukkan tampilan Mikrotik RB2011UiAS-RM.

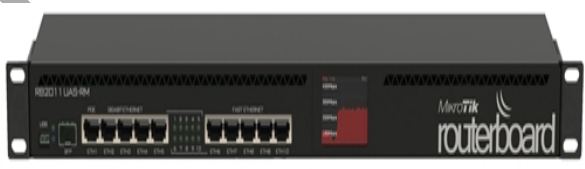

Gambar 3. Mikrotik RB2011UiAS-RM

\section{E. Bandwidth}

Bandwidth adalah nilai hitung atau perhitungan konsumsi transfer data telekomunikasi yang dihitung dalam satuan bit per detik atau yang biasa disingkat bps yang terjadi antara komputer server dan komputer client dalam waktu tertentu dalam sebuah jaringan komputer.

Bandwidth sendiri akan dialokasikan ke komputer dalam jaringan dan akan mempengaruhi kecepatan transfer data pada jaringan komputer tersebut sehingga semakin besar Bandwidth pada jaringan komputer maka semakin cepat pula kecepatan transfer data yang dapat dilakukan oleh client maupun server. Pada sebuah jaringan komputer bandwidth terbagi menjadi 2 yaitu bandwidth digital dan bandwidth analog.

\section{F. Internet Service Provider (ISP)}

ISP (Internet Service Provider). Untuk bisa bergabung dengan internet, kita harus mempunyai akses dengan cara berlangganan ke penyedia jasa internet (Internet Service Provider). ISP adalah perusahaan yang menawarkan jasa pelayanan kepada kita untuk berhubungan dengan internet. Untuk 
mengakses internet, kita cukup menghubungi ISP melalui modem dan komputer lalu ISP akan mengurus detail-detail yang diperlukan untuk berhubungan dengan internet, termasuk biaya koneksi tersebut. Jadi, misalnya kita sedang mengakses homepage luar negeri, maka ISP-lah yang menganggung biaya hubungan ke luar negeri. Kita cukup membayar pulsa lokal yang digunakan untuk menghubungi ISP tadi. Alur kerja ISP ditunjukkan pada Gambar 4. Saat ini telkom menyediakan fasilitasTelkomNet@Instan yang bersifat semi, yaitu akses internet melalui telkom tanpa harus berlangganan ke ISP tertentu, biaya pemakaian dihitung berdasarkan menit pemakaian.

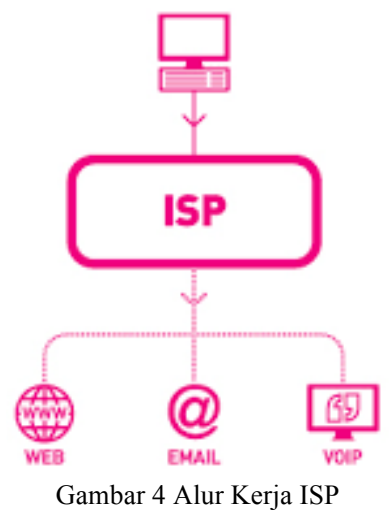

\section{PERANCANGAN PROGRAM APLIKASI}

\section{A. Deskripsi Program Aplikasi}

Load Balance pada Mikrotik adalah teknik untuk mendistribusikan beban trafik pada dua atau lebih jalur koneksi secara seimbang, agar trafik dapat berjalan optimal, memaksimalkan throughput, memperkecil waktu tanggap dan menghindari overload pada salah satu jalur koneksi.

Load Balance tidak akan menambah besar bandwidth yang diperoleh, tetapi hanya bertugas untuk membagi trafik dari kedua bandwidth tersebut agar dapat terpakai secara seimbang.

Dengan penulisan ini, penulis akan membuktikan bahwa dalam penggunaan Load Balancing tidak seperti rumus matematika $512+256$ $=768$, akan tetapi $512+256=512+256$, atau $512+$ $256=256+256+256$.

Pada penulisan ini Router Mikrotik yang digunakan adalah Mikrotik RB2011UiAS-RM dengan kondisi sebagai berikut :

1. Etherl dan Ether2 terhubung pada ISP yang berbeda dengan besar bandwdith yang berbeda. ISP 1 sebesar $512 \mathrm{kbps}$ dan ISP2 sebesar $256 \mathrm{kbps}$.

2. Mikrotik Router OS menggunakan versi 4.5 karena fitur PCC mulai dikenal pada versi 3.24.

\section{B. Cara Kerja Program Aplikasi}

Yang perlu dipahami dalam melakukan konfigurasi untuk PCC kuncinya adalah "perconnection-classifier=src-address-and-port:" selain itu juga dari sisi pembagian bandwidth dimana harus kita bagi secara merata, semisal dari ISP 1 kita mendapatkan bandwidth $768 \mathrm{kbps}$ sedangkan pada ISP 2 kita mendapatkan bandwidth 512kbps, maka agar merata pembagiannya untuk ISP $1256 \mathrm{kbps}+$ $256 \mathrm{kbps}+256 \mathrm{kbps}$ dan ISP 2 256kbps $+256 \mathrm{kbps}$ sehingga dari pembagian tersebut terdapat 5 koneksi dimana masing-masing bandwidth-nya 256kbps, sehingga untuk pembagiannya kurang lebih seperti berikut : 5/0,5/1,5/2,5/3,5/4. Langkah selanjutnya adalah kita membuat penandaan untuk semua trafik menggunakan mangle, tapi sebelum kita membuat penandaan, kita perlu membuat 2 buah rule NAT, jika kita sebelumnya sudah memilik koneksi ke satu provider, kita hanya perlu menambahkan rule NAT dengan action masquerade dimana untuk outinterface-nya di arahkan ke interface ethernet yang mengarah ke provider yang kedua, sebagai contoh seperti berikut :

/ip firewall nat add action=masquerade chain $=$ srcnat out-interface $=$ ether1 (mengarah ke ISP1)

ip firewall nat add action $=$ masquerade chain $=$ srcnat out-interface $=$ ether 2 (mengarah ke ISP2)

\section{Rancangan Program Aplikasi}

Load Balancing sendiri adalah teknik untuk mendistribusikan beban trafik pada dua atau lebih jalur koneksi secara seimbang, agar trafik dapat berjalan optimal, memaksimalkan throughput, memperkecil waktu tanggap dan menghindari agonize pada salah satu jalur koneksi. Selama ini kita beranggapan bahwa jika kita memiliki 2 koneksi dan menggabungkan antara kedua dengan bulk acclimation maka bandwidth kita menjadi dua kali lebih besar. Hal ini perlu kita perjelas dahulu, bahwa Load Balance tidak akan menambah besar bandwidth yang kita peroleh, tetapi hanya bertugas untuk membagi trafik dari kedua bandwidth tersebut agar dapat terpakai secara seimbang dan maksimal, dan untuk metode PCC adalah salah satu alternatif jika kita ingin menerapkan Load Balance dimana Mikrotik akan mengingat kembali koneksi sebelumnya untuk digunakan.

Topologi sistem pada Load Balancing ditunjukkan oleh Gambar 5. 


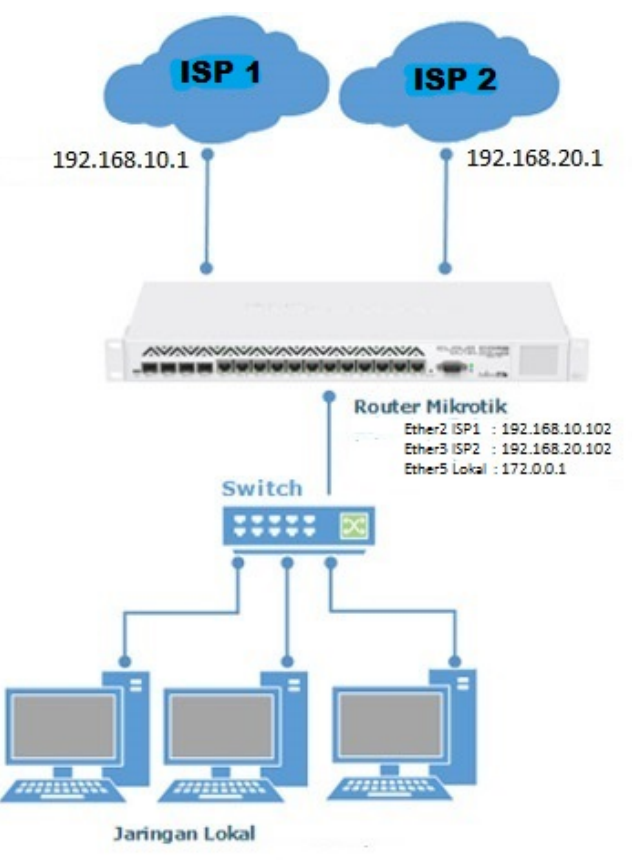

Gambar 5. Topologi Sistem Load Balancing

D. Realisasi Program Aplikasi

Pada bagian ini akan membahas langkah langkah yang akan ditempuh dalam upaya membangun sistem Load Balancing. Software yang digunakan untuk melakukan konfigurasi disini adalah Winbox. Setelah menginstall Winbox, maka tahap selanjutnya adalah melakukan konfigurasi Load Balancing menggunakan metode Per Connection Classifier.

\section{PENGUJAN}

\section{A. Deskripsi Pengujian}

Pengujian dilakukan dengan menggunakan 4 komputer serta software Mikrotik Bandwidth Test untuk mengetahui grafik bandwidth saat dilakukan pengunduhan. Komputer pertama dan kedua dijadikan sebagai ISP1 dan ISP2. Komputer 3 sebagai server yang digunakan untuk mengkonfigurasi Mikrotik, dan komputer 4 sebagai client yang akan melakukan pengujian sistem Load Balancing dengan metode Per Connection Classifier.

\section{B. Prosedur Pengujian}

Dalam melakukan proses pengujian menggunakan 4 komputer dan juga sebuah Mikrotik. Pertama setiap komputer dihubungkan dengan menggunakan Mikrotik. Lalu komputer client mengunduh sebuah file dari komputer 1, dan secara bersamaan client juga mengunduh file dari komputer 2. Pada saat melakukan pengunduhan akan terlihat bandwidth yang terbagi jika dilakukan pengunduhan secara bersamaan.

1. Pengujian Sistem Load Balancing Dengan Metode Per Connection Classifier (PCC).
Uji coba dilakukan dengan menjalankan software Mikrotik Bandwidth Test untuk mengetahui grafik bandwidth yang terdapat pada ISP1 dan ISP2. Setelah itu melakukan pengunduhan yang dilakukan komputer client kepada komputer 1. Selanjutnya pengunduhan kepada komputer 2. Jika sudah dilakukan pengunduhan secara bergantian, maka lakukan pengunduhan secara bersamaan. Lalu disitu akan terlihat bandwidth yang terbagi jika dilakukan pengunduhan secara bersamaan. Tampilan grafik bandwidth seperti pada Gambar 6.

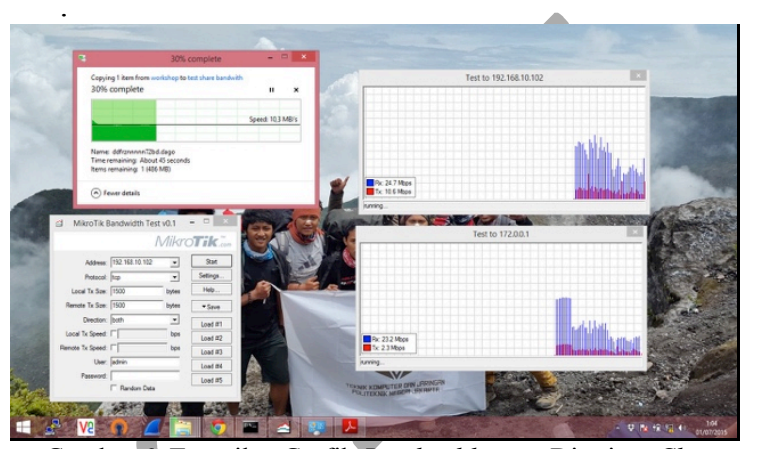

Gambar 6. Tampilan Grafik Bandwidth yang Diterima Client Ketika Melakukan Pengunduhan dari Komputer 1 dengan IP 192.168.10.102

\section{Pengujian pada sisi Mikrotik}

Uji coba yang dilakukan kurang lebih sama seperti uji coba sebelumnya. Namun pada uji coba kali ini dapat terlihat ISP mana yang sedang bekerja ketika client melakukan pengunduhan. Tampilan Interfaces List Ether3 sebagai ISP2 bekerja ketika dilakukan pengunduhan dari komputer 2 seperti ditunjukkan oleh Gambar 7.

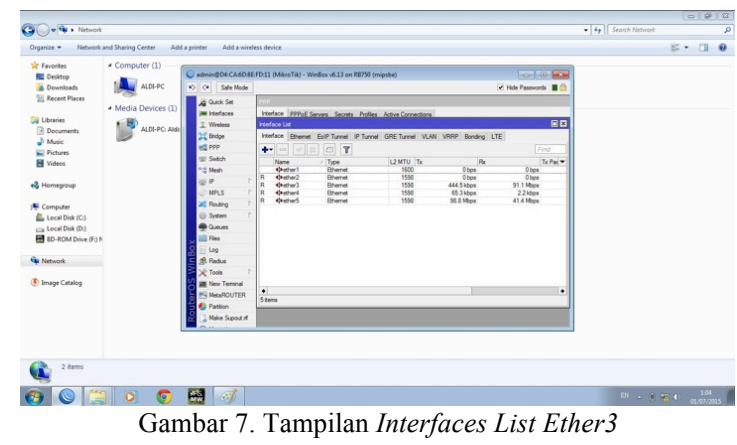

\section{Pengujian Ketika Salah Satu Koneksi Down}

Disini dapat dilihat ketika salah satu koneksi mati maka akan secara otomatis akan dialihkan kepada koneksi yang masih aktif. Ether3 sebagai ISP2 mengalami down maka seluruh beban akan dialihkan kepada Ether2 sebagai ISPI.

\section{Data Hasil Pengujian}

Berikut adalah hasil setelah melakukan pengujian sistem Load Balancing menggunakan metode Per Connection Classifier. Ketika dilakukan 
pengunduhan secara bersamaan maka bandwidth akan terbagi rata. Tampilannya seperti pada Gambar 8 .

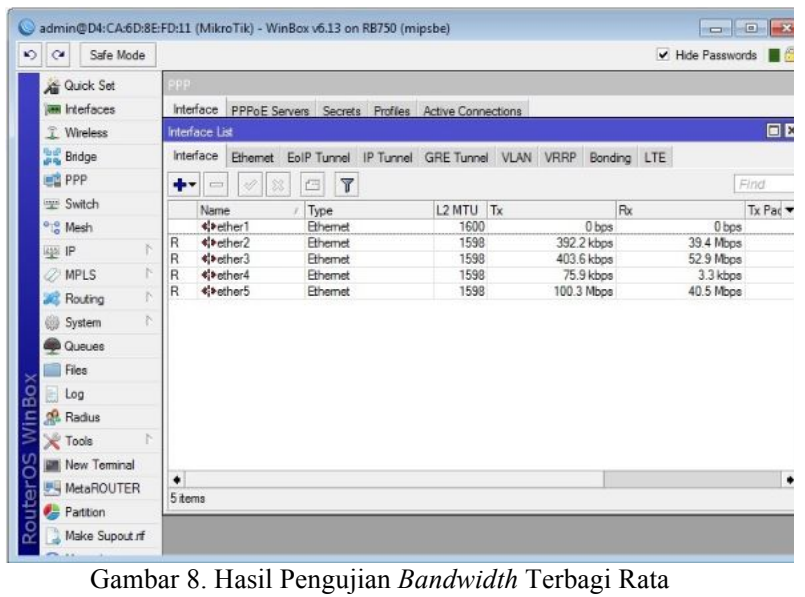

C. Analisis Data / Evaluasi

Dari hasil pengujian, sangat terlihat jelas pembagian bandwidth yang merata jika pengunduhan dilakukan lebih dari 1. Apabila hanya melakukan satu pengunduhan, maka bandwidth yang diterima akan lebih maksimal. Namun perlu diperhatikan disini, sistem Load Balancing dua ISP ini tidak menambahkan besar bandwidth menjadi 2 kali lipat dari sebelum menggunakan Load Balancing. Akan tetapi Load Balancing hanya bertugas membagi trafik dari kedua bandwidth tersebut agar dapat terpakai secara seimbang.

\section{KESIMPULAN DAN SARAN}

Berdasarkan uraian diatas dapat disimpulkan :

1. Penerapan sistem Load Balancing dengan metode PCC ini dapat membagi beban traffic secara seimbang sehingga dapat meningkatkan kecepatan internet.

2. Jika salah satu link jaringan internet terputus, maka seluruh beban akan dialihkan secara otomatis ke jaringan internet yang masih aktif.

3. Hubungan client server terjalin utuh karena selalu pada jalur yang sama, ini dikarenakan pada rule PCC akan selalu mengingat IP address sumber tujuan.

\section{REFERENSI}

[1] Chun-Cheng Lin, Hui-Hsin Chin, Der-Jiunn Deng, "Dynamic Multiservice Load Balancing in Cloud-Based Multimedia System”, IEEE Systems Journal , Vol. 8, Issue: 1, 2014, Pages: 225 - 234.

[2] Lukitasari, Desy \& Oklilas, Ahmad Fali. 2010. Analisis Perbandingan Load Balancing Web Server Tunggal Dengan Web server Cluster Menggunakan Linux Virtual Server. Universitas Sriwijaya : Jurnal Generic Fakultas Ilmu Komputer.

[3] Sirajuddin, Affandi, Ahmad, \& Setijadi, Eko. 2012. Rancang Bangun Server Learning Management System Menggunakan Load Balancer dan Reverse Proxy. Surabaya Jurnal Teknik POMITS Vol. 1, No. 1.

[4] Shancang Li; Shanshan Zhao; Xinheng Wang; Kewang Zhang; Ling Li, "Adaptive and Secure Load-Balancing Routing Protocol for Service-Oriented Wireless Sensor Networks". IEEE Systems Journal, Vol. 8, Issue: 3, 2014 , Pages: $858-867$.

[5] Hengky Susanto; Byung-Guk Kim, "Per-Connection Return Routability Test in Mobile IPv6.", International Conference on Network-Based Information Systems, 2009, Pages: $142-146$. 